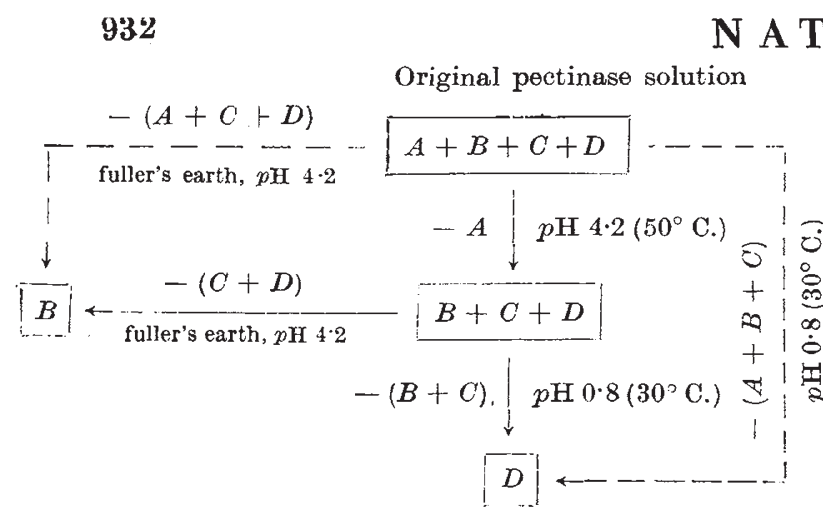

ity of the present polygalacturonase (Table 1). The activities diminish in the same manner when determined by the three methods mentioned above. The above scheme and Table 2 show some properties of the four polygalacturonases $A, B, C$ and $D$.

E. Schubert

Swiss Ferment Company, ltd., Basle.

Dec. 20 .

' Jertesz, Z. I., J. Amer. Chem. Soc., 61, 2544 (1939).

2 Jansen, E. F., and MacDonnel, L. R., Arch. Biochem., 8, 97 (1945).

Matus, J., Ber. Schweiz. Bot. Ges., 58, 319 (1948).

${ }^{4}$ McColloch, R. J., and Kertesz, Z. I., Arch. Biochem., 17, 197 (1948).

Reid, W. W., Nature, 166, 76 and 569 (1950).

${ }^{6}$ Schubert, L., Schweiz. Brauereirundschau, 62, 39 (1951).

'Schubert, E., Textilrundschau, 5, 1 (1950).

\section{Critical Evidence for Somatic Doubling of Chromosomes in a Top Yeast}

TETRAPLOINY was induced in our 2-chromosome control strain by treatment with acenaphthene ${ }^{1}$. As an off-shoot of this experiment, we were able to isolate a top yeast, $B Y 2$, which was diploid but had a pair of unequal chromosomes ${ }^{2}$. This inequality rendered it possible to offer critical evidence ${ }^{3}$ for mitosis in yeasts.

Spontaneous tetraploidy has been observed periodically ${ }^{4}$ in our control strain, $B Y$ 1. It was absent in the top yeast ${ }^{5}, B Y 2$. Recently, rare picturcs of somatic doubling of chromosomes were observed in smears of the top yeast, $B Y 2$, stained by the Feulgen technique $^{6}$ (Fig. 1). Proof of somatic doubling is

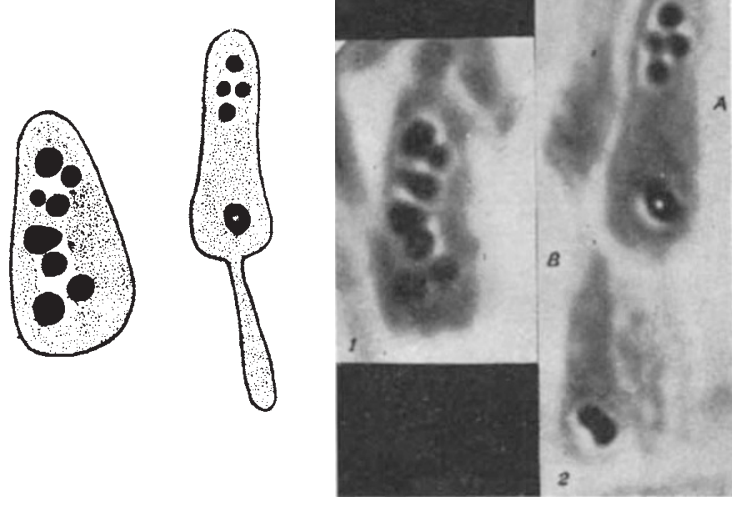

The cells in Figs. 1 and $2 A$ are $5 \cdot 1 \mu$ long
May 31, 1952 No. 4309 afforded by a demonstration of an anaphase of the doubled complement. Fig. 1 shows such an anaphase. The eight chromosomes appear in two groups, the one at the top showing two small and two large bodies. In the lower group, this size difference is not apparent, probably due to the swelling preceding a telophasic reconstitution. We should like to emphasize here that there is no strict synchronization in the timing of karyokinesis and cytokinesis.

This lack of correlation would become obvious in the cell $A$ in Fig. 2 , in which there is a reconstituted nucleus at one end near the bud, while the four chromosomes are lying free at the other end. At $B$ in the same photograph is a normal diploid early metaphase with two unequal chromosomes.

The mere fact that there is a somatic doubling does not entitle one to conclude that stable tetraploids could be isolated. Temporary somatic doubling may be followed by multipolar budding. The isolation of stable tetraploids depends on the primary condition that a doubled complement of chromosomes should be able to function harmoniously. Somatic doubling is thus only one of the conditions requisite for induction of tetraploidy. A gene mutation appears to be necessary to render the doubled complement a stable unit?

Our earlier claim of spontaneous and induced tetraploidy in yeasts does not appear to have been well received ${ }^{8}$. The main criticism is that we have not carried out crossing tests. Winge employed strains of unknown chromosomal constitution in his genetical investigations, but yet interpreted his results assuming them to be diploids. The mere isolation of spores and a study of their segregation ratios will not justify radical claims if the cytology of the strains has been ignored. The occurrence of spontaneous and induced tetraploidy in yeasts makes it necessary to know whether the spores isolated belong to diploids or to polyploids. The photographs presented here offer proof that somatic doubling of chromosomes is as common in yeasts as in higher plants.

\section{SARASWATHy ROYAN} M. K. SUBRAMANIAM

Cytogenetics Laboratory,

Department of Biochemistry,

Indian Institute of Science,

Bangalore 3. Dec. 3.

${ }^{2}$ Subramaniam, M. K., Curr. Sci., 14, 234 (1945); Proc. Nat. Inst. Sci., India, 13, 129 (1947).

2 Subramaniam. M. K., and Ranganathan, B., Nature, 157, 49 (1946); Proc. Nat. Inst. Sci. India, 14, 279 (1948).

${ }^{3}$ Royan, S., and Subramaniam, M. K., Curr. Sci., 20, 161 (1951).

${ }^{4}$ Prema Bai, M., and Subramaniam, M. K., Curr. Sci., 16, 380 (1947).

${ }^{5}$ Subramaniam, M. K., and Ranganathan, B., J. Sci. and Indust. Res., 9B, $4(1950)$.

- Subramaniam, M. K., Proc. Nat. Inst. Sci., India, 14, 315 (1948).

"Subramaniam, M. K., and Sreepathi Rao, S. K., Research, 3, 49 (1950).

${ }^{8}$ Winge, Ö., C.R. Lab. Carlsberg, Ser. Physiol., 25, 85 (1951).

\section{Lyophilic Properties of Isolated Serum- Protein Fractions}

EuECTROPHOREsts on paper of serum proteins has enabled us to separate small quantities into albumin, and $\alpha-, \beta$ - and $\gamma$-globulin. By using a comparatively thick filter paper (Munktell Nr. 20, Grycksbo, Sweden), $58 \mathrm{~cm}$. $\times 7 \mathrm{~cm}$., we can separate up to $30 \mathrm{mgm}$. of protein within $24 \mathrm{hr}$, with $5.5 \mathrm{~V}$. $\mathrm{cm}$. and $16-18$ m.amp. applied in a closed atmosphere. As buffer system veronal/veronal sodium is used, of 0.06 ionic 